\title{
PENENTUAN CADANGAN ASURANSI JIWA DWIGUNA DENGAN METODE COMMISSIONERS YANG MENGGUNAKAN FORMULA WOOLHOUSE
}

\author{
YELLY PRIMA DITA, RIRI LESTARI \\ Program Studi Matematika, \\ Fakultas Matematika dan Ilmu Pengetahuan Alam, Universitas Andalas, \\ Kampus UNAND Limau Manis Padang, Indonesia, \\ email : yellypd@gmail.com
}

\begin{abstract}
Abstrak. Asuransi jiwa merupakan salah satu perlindungan asuransi yang dikembangkan untuk pemecahan praktis, bertujuan untuk menanggung kerugian finansial tak terduga yang disebabkan oleh kematian. Salah satu jenis asuransi jiwa adalah asuransi dwiguna. Perlindungan berupa uang santunan yang bergantung pada premi yang dibayarkan. Formula Woolhouse adalah salah satu alat untuk menghitung nilai tunai anuitas dengan premi dibayarkan $m$ kali dalam setahun. Sebagian dari premi yang dibayarkan akan digunakan sebagai cadangan. Perhitungan cadangan menggunakan cadangan commissioners.
\end{abstract}

Kata Kunci: Formula Woolhouse, cadangan commissioners

\section{Pendahuluan}

Asuransi jiwa merupakan salah satu perlindungan asuransi yang dikembangkan untuk pemecahan praktis, bertujuan untuk menanggung kerugian finansial tak terduga yang disebabkan oleh kematian, kecelakaan atau mengalami cacat tetap. Salah satu asuransi jiwa adalah asuransi jiwa dwiguna. Asuransi jiwa diwiguna adalah asuransi yang memberikan uang santunan apabila pemegang polis meninggal ataupun bertahan hidup Dalam mengikuti program asuransi jiwa, terdapat sejumlah uang yang harus dibayarkan setiap periode oleh pemegang polis asuransi yang disebut dengan premi. Perhitungan premi sangat dipengaruhi oleh jenis asuransi jiwa dan anuitas. Anuitas merupakan rangkaian pembayaran atau penerimaan dana tetap dalam jumlah tertentu yang dilakukan secara berkala pada jangka waktu tertentu [1].

Berdasarkan banyaknya pembayaran premi yang dilakukan dalam setahun, peserta asuransi jiwa dapat melakukan pembayaran premi $m$ kali pembayaran dalam setahun. Untuk menentukan nilai tunai anuitas dan premi dengan pembayaran premi sebanyak $m$ kali dalam setahun dapat digunakan Formula Woolhouse. Premi yang telah terkumpul dari peserta asuransi akan disimpan sebagai cadangan premi yang akan digunakan untuk membayar uang pertanggungan ketika terjadi klaim. Premi yang diterima perusahaan asuransi dari pemegang polis tidak cukup untuk menutupi biaya pada awal tahun karena premi yang dibutuhkan untuk cadangan pada tahun pertama lebih besar dari premi tahun pertama. Oleh karena itu ca- 
dangan premi perlu dimodifikasi. Salah satu metode cadangan premi adalah cadangan commissioners yang menyatakan hubungan antara premi bersih dan premi modifikasi.

\section{Nilai Tunai Anuitas Dan Premi Dengan Formula Woolhouse}

Pada bagian ini akan dibahas mengenai premi asuransi jiwa dwiguna dan formula Woolhouse. Akan tetapi akan diberikan terlebih dahulu nilai tunai anuitas yang dipengaruhi oleh peluang dan faktor diskon.

Anuitas seumur hidup merupakan anuitas yang pembayaran preminya dilakukan selama seseorang masih hidup. Nilai tunai anuitas awal seumur hidup seseorang berusia $x$ tahun dapat dinyatakan dengan [1]:

$$
\ddot{a}_{x}=\sum_{t=0}^{\infty} v^{t}{ }_{t} p_{x} .
$$

Nilai tunai anuitas awal seumur hidup dalam bentuk komutasi dapat dinyatakan dengan:

$$
\ddot{a}_{x}=\frac{N_{x}}{D_{x}}
$$

Nilai tunai anuitas awal seumur hidup untuk seseorang berusia $x$ tahun dengan pembayaran premi $m$ kali dalam setahun dapat dinyatakan dengan [2]:

$$
\ddot{a}_{x}^{(m)}=\frac{1}{m} \sum_{t=0}^{\infty} v_{t / m}^{t / m} p_{x}
$$

Anuitas hidup berjangka merupakan anuitas yang pembayaran preminya dilakukan dalam jangka waktu tertentu. Nilai tunai anuitas awal berjangka seseorang berusia $x$ tahun dengan jangka waktu pertanggungan $n$ periode dapat dinyatakan dengan [1]:

$$
\ddot{a}_{x: \bar{n} \mid}=\sum_{t=0}^{n-1} v^{t}{ }_{t} p_{x} .
$$

Nilai tunai anuitas awal berjangka dalam bentuk komutasi dapat dinyatakan dengan:

$$
\ddot{a}_{x: \bar{n} \mid}=\frac{N_{x}-N_{x+n}}{D_{x}}
$$

Nilai tunai anuitas awal berjangka untuk seseorang berusia $x$ tahun dan jangka waktu pertanggungan $n$ periode dengan pembayaran premi $m$ kali dalam setahun dapat dinyatakan dengan [1]:

$$
\ddot{a}_{x: \bar{n} \mid}^{(m)}=\frac{1}{m} \sum_{t=0}^{n m-1} v_{t / m}^{t / m} p_{x} .
$$

Untuk menentukan nilai tunai anuitas $m$ kali pembayaran pertahun, digunakan formula Woolhouse. Formula Woolhouse merupakan suatu formula yang diperoleh dari pengembangan Euler-Maclaurin dimana pada prosesnya dilakukan pendekatan 
terhadap suatu fungsi yang terdiferensialkan hingga turunan ke- $n$. Formula Woolhouse dinyatakan sebagai berikut [1]:

$$
\int_{a}^{b} g(x) d x=h \sum_{t=0}^{\infty} g(t h)-\frac{h}{2} g(0)+\frac{h^{2}}{12} g^{\prime}(0) .
$$

Misalkan terdapat suatu fungsi $g(t)$ yang menyatakan nilai tunai anuitas pembayaran premi sekali dalam setahun. Berdasarkan persamaan (1), maka fungsi tersebut dinyatakan dengan:

$$
g(t)=v^{t}{ }_{t} p_{x}
$$

Dengan menurunkan fungsi $g(t)$ pada saat $t=0$ diperoleh:

$$
g^{\prime}(0)=-\left(\delta+\mu_{x}\right)
$$

Dengan mensubstitusikan persamaan (9) ke persamaan (7), untuk pembayaran premi sekali setahun maka $h=1$ dan $g(0)=1$ sehingga diperoleh:

$$
\int_{a}^{b} g(x) d x=\sum_{t=0}^{\infty} g(t)-\frac{1}{2}-\frac{1}{12}\left(\delta+\mu_{x}\right) .
$$

Selanjutnya untuk pembayaran premi $m$ kali setahun maka $h=\frac{1}{m}$ dan $g(0)=1$ sehingga diperoleh:

$$
\int_{a}^{b} g(x) d x=\frac{1}{m} \sum_{t=0}^{\infty} g\left(\frac{t}{m}\right)-\frac{1}{2 m}-\frac{1}{12 m^{2}}\left(\delta+\mu_{x}\right) .
$$

Persamaan (9) dan (10) mempunyai nilai yang kurang lebih sama sehingga dapat ditulis menjadi:

$$
\frac{1}{m} \sum_{t=0}^{\infty} g\left(\frac{t}{m}\right)-\frac{1}{2 m}-\frac{1}{12 m^{2}}-\left(\delta+\mu_{x}\right)=\sum_{t=0}^{\infty} g(t)-\frac{1}{2}-\frac{1}{12}\left(\delta+\mu_{x}\right) .
$$

Berdasarkan persamaan (6) maka persamaan (12) dapat diturunkan menjadi:

$$
\frac{1}{m} \sum_{t=0}^{\infty} v^{t / m}{ }_{t / m} p_{x}=\sum_{t=0}^{\infty} v_{t}^{t} p_{x}-\frac{m-1}{2 m}-\frac{m^{2}-1}{12 m^{m}}\left(\delta+\mu_{x}\right)
$$

Nilai tunai anuitas seumur hidup dengan formula Woolhouse untuk seseorang berusia $x$ tahun dengan pembayaran premi dilakukan $m$ kali dalam setahun dapat diperoleh dengan mensubstitusikan persamaan (1) dan (3) sehingga diperoleh:

$$
\ddot{a}_{x}^{(m)}=\ddot{a}_{x}-a-b\left(\delta+\mu_{x}\right)
$$

dengan $a=\frac{m-1}{2 m}$ dan $b=\frac{m^{2}-1}{12 m^{2}}$.

Selanjutnya untuk memperoleh nilai tunai anuitas seumur hidup dalam bentuk komutasi dengan premi yang dibayarkan $m$ kali dalam setahun menggunakan formula Woolhouse dapat diperoleh:

$$
\ddot{a}_{x}^{(m)}=\frac{N_{x}}{D_{x}}-a-b\left(\delta+\mu_{x}\right) .
$$


Nilai tunai anuitas seumur hidup untuk seseorang berusia $x+n$ tahun dengan formula Woolhouse adalah:

$$
\ddot{a}_{x+n}^{(m)}=\ddot{a}_{x+n}-a-b\left(\delta+\mu_{x+n}\right)
$$

Hubungan antara nilai tunai anuitas seumur hidup dengan nilai tunai anuitas berjangka adalah:

$$
\ddot{a}_{x: \bar{n} \mid}^{(m)}=\ddot{a}_{x}^{(m)}-v^{n}{ }_{n} p_{x}
$$

Nilai tunai anuitas berjangka untuk seseorang berusia $x$ tahun dan jangka waktu pertanggungan $n$ periode dengan pembayaran premi $m$ kali setahun menggunakan formula Woolhouse adalah:

$$
\ddot{a}_{x: n \mid}^{(m)}=\ddot{a}_{x: \bar{n} \mid}-a\left(1-v_{n}^{n} p_{x}\right)-b\left(\delta+\mu_{x}-v^{n}{ }_{n} p_{x}\left(\delta+\mu_{x+n}\right)\right.
$$

Nilai tunai anuitas berjangka dalam bentuk komutasi untuk seseorang berusia $x$ tahun dan jangka waktu pertanggungan $n$ periode dengan pembayaran premi $m$ kali setahun menggunakan formula Woolhouse adalah:

$$
\ddot{a}_{x: n \mid}^{(m)}=\frac{N_{x}-N_{x+n}}{D_{x}}-a\left(1-v^{n}{ }_{n} p_{x}\right)-b\left(\delta+\mu_{x}-v^{n}{ }_{n} p_{x}\left(\delta+\mu_{x+n}\right)\right.
$$

Nilai tunai anuitas berjangka dengan masa pembayaran premi $h$ tahun dengan menggunakan formula Woolhouse adalah:

$$
\ddot{a}_{x: \bar{h} \mid}^{(m)}=\frac{N_{x}-N_{x+h}}{D_{x}}-a\left(1-v^{h}{ }_{h} p_{x}\right)-b\left(\delta+\mu_{x}-v^{h}{ }_{h} p_{x}\left(\delta+\mu_{x+h}\right)\right.
$$

Nilai tunai anuitas berjangka untuk seseorang berusia $x+t$ tahun dengan jangka waktu pembayaran premi $h-t$ tahun apabila premi dibayarkan $m$ kali dalam setahun dengan menggunakan formula Woolhouse diperoleh:

$$
\begin{aligned}
\ddot{a}_{x+t: \overline{h-t \mid}}^{(m)}= & \frac{N_{x+t}-N_{x+h}}{D_{x+t}}-a\left(1-v^{h-t}{ }_{h-t} p_{x}+n\right) \\
& -b\left(\delta+\mu_{x+n}-v^{h-t}{ }_{h-t} p_{x}\left(\delta+\mu_{x+h}\right)\right.
\end{aligned}
$$

Berdasarkan pembayaran premi, premi terbagi menjadi premi tunggal dan premi tahunan. Premi tunggal adalah premi yang pembayarannya dibayarkan sekaligus. Premi tunggal asuransi jiwa dwiguna dalam bentuk komutasi dapat dinyatakan dengan:

$$
A_{x: \bar{n} \mid}=1-d\left(\frac{N_{x+t}-N_{x+h}}{D_{x+t}}\right)
$$

Premi tunggal bersih untuk seseorang berusia $x+t$ tahun dengan jangka waktu pertanggungan $n-t$ periode dengan formula Woolhouse dapat dinyatakan dengan:

$$
A_{x+t: \overline{n-t} \mid}=1-d\left(\frac{N_{x+t}-N_{x+h}}{D_{x+t}}-a\left(1-v^{n}{ }_{n} p_{x}\right)-b\left(\delta+\mu_{x}-v^{n}{ }_{n} p_{x}\left(\delta+\mu_{x+n}\right)\right.\right.
$$

Selanjutnya premi tunggal asuransi seumur hidup untuk seseorang berusia $x$ tahun dalam bentuk komutasi dapat dinyatakan dengan:

$$
A_{x}=1-d\left(\frac{N_{x}}{D_{x}}\right)
$$


Premi tahunan adalah premi yang pembayarannya dilalukan pertahun. Premi tahunan untuk seseorang berusia $x$ tahun dengan lama pertanggungan $n$ tahun dan jangka pembayaran premi $h$ tahun dengan menggunakan formula Woolhouse diperoleh:

$$
{ }_{h} P_{x: \bar{n} \mid}{ }^{(m)}=\frac{1-d\left(\frac{N_{x}-N_{x+n}}{D_{x}}\right)}{\frac{N_{x}-N_{x+h}}{D_{x}}-a\left(1-v^{h}{ }_{h} p_{x}\right)-b\left(\delta+\mu_{x}-v^{h}{ }_{h} p_{x}\left(\delta+\mu_{x+h}\right)\right.}
$$

Premi tahunan asuransi jiwa seumur hidup untuk seseorang berusia $x+1$ tahun dengan formula Woolhouse dapat dinyatakan dengan:

$$
{ }_{h} P_{x+1}{ }^{(m)}=\frac{1-d\left(\frac{N_{x+1}}{D_{x+1}}\right)}{\frac{N_{x+1}-N_{x+1+h}}{D_{x+1}}-a\left(1-v^{h}{ }_{h} p_{x+1}\right)-b\left(\delta+\mu_{x+1}-v^{h}{ }_{h} p_{x+1}\left(\delta+\mu_{x+1+h}\right)\right.}
$$

\section{Cadangan commissioners dengan Formula Woolhouse}

Cadangan adalah sebagian uang yang disimpan dalam perusahaan asuransi selama periode tertentu. Cadangan pada akhir tahun ke $t$ dengan pembayaran $m$ kali dalam setahun adalah [2]:

$$
{ }_{t} V_{x \bar{n} \mid}^{(m)}=A_{x+t: \overline{h-t \mid}}^{(m)}-P_{x \bar{n} \mid}^{(m)} \ddot{a}_{x+t: \overline{h-t \mid}}^{(m)}
$$

Berdasarkan persamaan (27) untuk premi yang dibayarkan selama $h$ tahun untuk $h<n$, maka cadangan pada akhir tahun ke $t$ adalah:

$$
{ }_{t}^{h} V_{x \bar{n} \mid}{ }^{(m)}=A_{x+t: \overline{h-t \mid}}^{(m)}-{ }_{h} P_{x \bar{n} \mid}^{(m)} \ddot{a}_{x+t: \overline{h-t \mid}}^{(m)}
$$

Salah satu cadangan modifikasi adalah cadangan commissioners. Cadangan commissioners selisih antara $\beta$ modifikasi dan $\alpha$ modifikasi untuk sembarang polis yang diberikan dan usia pada saat dikeluarkan setara dengan selisih antara premi bersih asuransi seumur hidup dengan masa pembayaran 19 tahun yang dikeluarkan pada usia satu tahun lebih tinggi dan premi bersih berjangka satu tahun yang dikeluarkan pada usia awal. Metode commissioners dinyatakan [2] dengan persamaan:

$$
\beta^{c o m}-\alpha^{c o m}={ }_{19} P_{x+1}-c_{x}
$$

dengan $c_{x}$ merupakan premi natural, yaitu premi berjangka satu tahun. Premi natural dinyatakan dengan:

$$
c_{x}=v q_{x}
$$

Berdasarkan persamaan (29), metode commissioners dengan $m$ kali pembayaran premi pertahun adalah:

$$
\begin{aligned}
& \beta^{c o m(m)}-\alpha^{\operatorname{com}(m)}={ }_{19} P_{x+1}{ }^{(m)}-c_{x}{ }^{(m)} \\
& \alpha^{\operatorname{com}(m)}=\beta^{\operatorname{com}(m)}-{ }_{19} P_{x+1}{ }^{(m)}+c_{x}{ }^{(m)}
\end{aligned}
$$


dengan $c_{x}{ }^{(m)}$ merupakan premi natural, yaitu premi berjangka satu tahun dengan $m$ kali pembayaran dalam setahun dapat dinyatakan dengan:

$$
c_{x}{ }^{(m)}=1-d^{(m)} \ddot{a}_{x: \overline{1} \mid}^{(m)}-v p_{x}
$$

dengan $d^{(m)}$ adalah tingkat diskonto dengan pembayaran premi $m$ kali premi pertahun dan dapat dinyatakan dengan:

$$
d^{(m)}=m\left(1-(1-d)^{(1 / m)}\right)
$$

Nilai tunai premi bersih $m$ kali pembayaran premi sama dengan premi modifikasi berdasarkan metode commissioners dengan $m$ kali pembayaran dapat dinyatakan sebagai berikut:

$$
\alpha^{\operatorname{com}(m)}+\beta^{\operatorname{com}(m)}\left(\ddot{a}_{x: \bar{h} \mid}-1\right)={ }_{h} P_{x \bar{n} \mid}^{(m)} \ddot{a}_{x \bar{h} \mid}^{(m)}
$$

Substitusikan persamaan (31) ke persamaan (34) sehingga diperoleh premi modifikasi $m$ kali pembayaran premi dalam setahun dengan metode commissioners dapat dinyatakan dengan:

$$
\beta^{\operatorname{com}(m)}={ }_{h} P_{x \bar{n} \mid}^{(m)}+\frac{{ }_{19} P_{x+1}{ }^{(m)}-c_{x}{ }^{(m)}}{\ddot{a}_{x: \bar{h} \mid}}
$$

Berdasarkan persamaan (28), cadangan commissioners pada akhir tahun ke tasuransi jiwa dwiguna untuk seseorang berusia $x$ tahun dengan jangka waktu pertanggungan $n$ tahun dan jangka waktu pembayaran premi $h$ tahun untuk $t<h$ dapat dinyatakan dengan:

$$
{ }_{t}^{h} V_{x \bar{n} \mid}{ }^{(m)}=A_{x+t: \overline{h-t \mid}}^{(m)}-\beta^{\operatorname{com}(m)} \ddot{a}_{x+t: \overline{h-t \mid}}^{(m)}
$$

dan untuk $t \geq h$ cadangan commissioners pada akhir tahun ke $t$ dapat dinyatakan dengan:

$$
{ }_{t}^{h} V_{x \bar{n} \mid}{ }^{(m)}=A_{x+t: \overline{h-t \mid}}^{(m)}
$$

Dengan mensubstitusikan persamaan (21) dan (23) ke persamaan (36) maka diperoleh cadangan commissioners dengan formula Woolhouse untuk $t<h$ adalah:

$$
\begin{aligned}
{ }_{t}^{h} V_{x \bar{n} \mid}{ }^{(m)}= & 1-d^{(m)}\left(\frac{N_{x+t}-N_{x+h}}{D_{x+t}}-a\left(1-v^{n}{ }_{n} p_{x}\right)-b\left(\delta+\mu_{x+t}-v^{n}{ }_{n} p_{x}\left(\delta+\mu_{x+n}\right)\right.\right. \\
& -\beta^{\operatorname{com}(m)} \frac{N_{x+t}-N_{x+h}}{D_{x+t}}-a\left(1-v^{h-t}{ }_{h-t} p_{x}+n\right)-b\left(\delta+\mu_{x+n}-v^{h-t}{ }_{h-t} p_{x}\left(\delta+\mu_{x+h}\right)\right.
\end{aligned}
$$

dan untuk $t \geq h$ cadangan commissioners dengan formula Woolhouse dapat dinyatakan dengan:

${ }_{t}^{h} V_{x \bar{n} \mid}{ }^{(m)}=1-d^{(m)}\left(\frac{N_{x+t}-N_{x+h}}{D_{x+t}}-a\left(1-v^{n}{ }_{n} p_{x}\right)-b\left(\delta+\mu_{x+t}-v^{n}{ }_{n} p_{x}\left(\delta+\mu_{x+n}\right)\right.\right.$ 


\section{Ilustrasi Kasus}

Seseorang laki-laki yang berusia 40 tahun mengikuti program asuransi jiwa dwiguna selama 25 tahun dengan jangka waktu pembayaran premi 20 tahun. Uang santunan yang diharapkan adalah Rp. 100.000.000,00. Akan ditentukan cadangan commissioners dengan pembayaran premi sekali setahun dan cadangan commissioners dengan menggunakan formula Woolhouse apabila pembayaran dilakukan enam kali dalam setahun.

(1) Cadangan commissioners dengan premi yang dibayarkan sekali dalam setahun.

Premi modifikasi dengan metode commissioners adalah

$$
\begin{aligned}
\beta^{\text {com }} & ={ }_{20} P_{40: \overline{25} \mid}+\frac{{ }_{19} P_{40+1}-c_{40}}{\ddot{a}_{40: \overline{25}}} \\
& =R p .100 .000 .000\left(0,0380481767+\frac{0,029257152}{0,0014492668}\right) \\
& =\text { Rp. 3.804.817,67 }
\end{aligned}
$$

Cadangan commissioners asuransi jiwa dwiguna dengan pembayaran premi pertahun untuk $t<h$ dengan mengambil $\mathrm{t}=4$ yaitu

$$
{ }_{4}^{20} V_{40 \overline{25} \mid}=A_{40+4: \overline{20-4 \mid}}-\beta^{c o m} \ddot{a}_{40+4: \overline{20-4 \mid}}=R p .12 .415 .937,21
$$

Cadangan commissioners asuransi jiwa dwiguna dengan pembayaran premi pertahun untuk $t \geq h$ dengan mengambil $\mathrm{t}=22$ yaitu

$$
\begin{gathered}
{ }_{4}^{20} V_{40 \overline{25} \mid}=A_{40+22: \overline{20-22 \mid}}- \\
\quad=\operatorname{Rp} .92 .974 .735,88
\end{gathered}
$$

(2) Cadangan commissioners dengan formula Woolhouse premi yang dibayarkan $m$ dalam setahun. Premi modifikasi cadangan commissioners dengan formula Woolhouse adalah:

$$
\begin{aligned}
\beta^{c o m}(m) & ={ }_{20} P_{40: \overline{25} \mid}{ }^{(m)}+\frac{{ }_{19} P_{40+1}^{m}-c_{40}{ }^{(m)}}{\ddot{a}_{40: \overline{25} \mid}^{(m)}} \\
& =\text { Rp. } 100.000 .000\left(0,0380481767+\frac{0,029257152}{0,0014492668}\right) \\
& =\text { Rp. } 3.804 .817,67
\end{aligned}
$$

Cadangan commissioners asuransi jiwa dwiguna dengan pembayaran premi $m$ kali pertahun untuk $t<h$ dengan mengambil $\mathrm{t}=4$ yaitu

$$
{ }_{4}^{20} V_{40 \overline{25} \mid}{ }^{(m)}=A_{40+4: \overline{20-4 \mid}}^{(m)}-\beta^{c o m(m)} \ddot{a}_{40+4: \overline{20-4 \mid}}^{m}=R p .12 .626 .571,71
$$

Cadangan commissioners asuransi jiwa dwiguna dengan pembayaran premi $m$ kali pertahun untuk $t \geq h$ dengan mengambil $\mathrm{t}=22$ yaitu

$$
\begin{gathered}
{ }_{4}^{20} V_{40 \overline{25} \mid}{ }^{(m)}=A_{40+22: \overline{20-22 \mid}}^{(m)} \\
\quad=R p .93 .028 .488,78
\end{gathered}
$$




\begin{tabular}{|c|c|c|}
\hline Tahun & $\begin{array}{l}\text { Cadangan Commissioners } \\
\text { dengan premi sekali } \\
\text { setahm }\end{array}$ & $\begin{array}{l}\text { Cadangan Commissioners dengan } \\
\text { premin } 6 \text { kali setahu (formula } \\
\text { Woolhouse) }\end{array}$ \\
\hline 1 & $902.469,83$ & $1.097 .776,78$ \\
\hline$\frac{1}{2}$ & $4.658 .169,74$ & $4.858 .957,63$ \\
\hline 3 & $8.495 .299,63$ & $8.701 .216,51$ \\
\hline 4 & $12.415 .937,21$ & $12.626 .571,71$ \\
\hline 5 & $16.420 .835,28$ & $16.635 .687,65$ \\
\hline 6 & $20.509 .723,72$ & $20.728 .155,65$ \\
\hline 7 & $24.683 .146,56$ & $24.904 .395,77$ \\
\hline 8 & $28.942 .516,68$ & $29.165 .642,60$ \\
\hline 9 & $33.290 .174,69$ & $33.514 .008,76$ \\
\hline 10 & $37.729 .453,13$ & $37.952 .668,66$ \\
\hline 11 & $42.262 .425,15$ & $42.483 .425,73$ \\
\hline 12 & $46.892 .786,72$ & $47.109 .701,20$ \\
\hline 13 & $51.627 .439,97$ & $51.838 .193,50$ \\
\hline 14 & $56.477 .415,20$ & $56.679 .840,79$ \\
\hline 15 & $61.453 .783,59$ & $61.645 .528,30$ \\
\hline 16 & $66.569 .467,78$ & $66.748 .058,16$ \\
\hline 17 & $71.838 .385,37$ & $72.001 .179,98$ \\
\hline 18 & $77.275 .545,19$ & $77.419 .714,55$ \\
\hline 19 & $82.897 .500,22$ & $83.020 .156,34$ \\
\hline 20 & $88.721 .664,96$ & $88.801 .945,17$ \\
\hline 21 & $90.810 .399,35$ & $90.878 .175,91$ \\
\hline 22 & $92.974 .735,88$ & $93.028 .488,78$ \\
\hline 23 & $95.221 .741,63$ & $95.259 .718,70$ \\
\hline 24 & $97.560 .000,00$ & $97.580 .172,18$ \\
\hline 25 & $100.000 .000,00$ & $100.000 .000,00$ \\
\hline
\end{tabular}

Gambar 1. Cadangan commissioners dan cadangan commissioners dengan formula Woolhouse untuk pria berusia 40 tahun.

Cadangan commissioners dengan formula Woolhouse untuk peserta asuransi berusia 40 tahun, masa pertanggungan 25 tahun dan masa pembayaran premi 20 tahun dapat dilihat pada Tabel 1 .

\section{Kesimpulan}

Pada jurnal ini, dibahas tentang perhitungan cadangan premi menggunakan metode commissioners yang merupakan perluasan dari metode prospektif dengan menggunakan formula Woolhouse. Nilai tunai anuitas yang ditentukan dengan formula Woolhouse merupakan nilai tunai anuitas dengan pembayaran $\mathrm{m}$ kali dalam setahun. Nilai tunai anuitas dengan formula Woolhouse dipengaruhi oleh tingkat suku bunga, percepatan pembungaan, percepatan mortalitas, peluang hidup, dan banyaknya pembayaran pertahun. Dari premi dengan formula Woolhouse, dapat ditentukan cadangan commissioners.

\section{Ucapan Terima kasih}

Penulis mengucapkan terima kasih kepada Ibu Yanita, Bapak Dodi Devianto, Bapak Syafrizal Sy, dan Bapak Ahmad Iqbal Baqi yang telah memberikan masukan dan saran sehingga paper ini dapat diselesaikan dengan baik.

\section{Daftar Pustaka}

[1] Dickson, D.C., M. R. Waters. 2009. Actuarial Mathematics for Life Contingent Risks. Cambridge University Pres, New York.

[2] Menge, W.O., C. H. Fisher 1993. The Mathematics of Life Insurance. Ulrichs Books Inc, USA. 